\title{
Divulgação de Informações por Segmento: Panorama da Aplicação do CPC 22
}

\section{Resumo}

O objetivo da pesquisa foi traçar um panorama da divulgação de segmentos nas demonstrações financeiras das companhias abertas que operam no Brasil, publicadas em 2010, primeiro ano de vigência do CPC 22. Para isso procurou-se identificar como foram definidos e quantos são os segmentos publicados, além de analisar tais resultados em relação a características corporativas da empresa: tamanho, setor de atuação e status de listagem da companhia nos níveis de governança corporativa. Trata-se de pesquisa bibliográfica e documental com foco descritivo. $\mathrm{O}$ levantamento dos dados foi realizado em notas explicativas de 81 companhias abertas selecionadas entre as maiores empresas, na edição 2010 da Revista Melhores e Maiores. A análise dos dados foi realizada com estatística descritiva e análise de correlação. Os resultados da pesquisa mostraram que há empresas que não fizeram qualquer referência a informações por segmentos. A definição dos segmentos atendeu predominantemente ao critério de linha de negócios, e 27\% das companhias agruparam as atividades em um único segmento. A análise da correlação mostrou que somente o tamanho do ativo apresentou relacionamento significante e positivo com as características de definição e quantidade de segmentos publicados. Constatou-se que há grande heterogeneidade nas estruturas dos relatórios por segmento publicados.

Palavras chave: Evidenciação contábil, Relatório por segmentos, CPC 22, IFRS 8.

\section{Eliandro Schvirck \\ Mestrado em Controladoria e Contabilidade (FEA/USP), Doutorando em Administração (CPGA/UFSC), Professor da Universidade Tecnológica Federal do Paraná (UTFPR). Contato: Via do Conhecimento, Km 01, Fraron, Pato Branco, PR, Brasil, CEP: 85503-390. E-mail: eliandro@utfpr.edu.br}

\section{Rogério João Lunkes}

Pós-doutorado em Universidade de Valencia, Professor da Universidade Federal de Santa Catarina (UFSC). Contato: Campus Universitário Reitor João David Ferreira Lima, SSE/DCC, Trindade, Florianópolis, SC, Brasil, CEP: 88040-900. E-mail: lunkes@cse.ufsc.br

\section{Valdirene Gasparetto} Doutorado em Engenharia de Produção (UFSC), Professor da Universidade Federal de Santa Catarina (UFSC). Contato: Campus Universitário Reitor João David Ferreira Lima, CSE/DCC, Trindade, Florianópolis, SC, Brasil, CEP: 88040-900. E-mail: valdirene@cse.ufsc.br 


\section{Introdução}

O mercado de capitais no Brasil tem se expandido devido à abertura de capital de diversas empresas, entrada de novos investidores no mercado, busca por capacitação para atuar no mercado, entre outros fatores. Conforme explicado por Lélis, Colauto, Pinheiro e Jordão (2008) o forte desenvolvimento do mercado de capitais, em países economicamente desenvolvidos e emergentes, faz com que a evidenciação financeira das informações de forma compulsória ou voluntária, seja cada vez mais requerida pelo mercado, a fim de possibilitar uma maior transparência aos investidores.

A melhora no nível de evidenciação de informações ao mercado passa, frequentemente, pela normatização de procedimentos. Seguindo essa premissa e como parte da adoção das normas internacionais de contabilidade (International Financial Reporting Standards - IFRS) pelas empresas brasileiras, foi instituído o CPC 22 - Informações por Segmento. De acordo com esse pronunciamento, as companhias abertas brasileiras, a partir do exercício de 2010, devem publicar como parte de suas demonstrações anuais, as informações por segmento.

Iudícibus, Martins, Gelbcke e Santos (2010, p. 628) explicam que

o processo de harmonização das normas de contabilidade em âmbito internacional traz ao contador e gestores uma nova postura, cujo julgamento, relevância e reflexo econômico são priorizados em detrimento aos padrões normativos estabelecidos anteriormente.

Assim, seguindo os preceitos das normas internacionais, agora adotadas no Brasil por meio dos pronunciamentos do Comitê de Pronunciamentos Contábeis (CPC), os gestores e contadores decidirão de acordo com a essência econômica do fato prioritariamente em relação às regras e normas.

Concomitante a isso, o relatório por segmento deve ser elaborado com os dados utilizados para a tomada de decisões internas, ou seja, com abordagem gerencial, independente de normas fiscais ou tributárias, possibilitando assim poder discricionário aos gestores. Como exposto por Iudícibus et al. (2010, p. 628), "a ideia principal é que sejam propiciadas aos usuários informações em caráter gerencial [...] utilizadas pelos gestores da empresa nas decisões cotidianas".

O CPC 22, ao transcrever o IFRS 8, não define um padrão de formato e de dados a serem divulgados pelas organizações, partindo do pressuposto de que cada empresa possui uma estrutura interna para tomada de decisão específica ao seu modelo de gestão, o qual deve nortear essa divulgação.

Esta falta de padrão na divulgação pode ser demonstrada pelo estudo de Talha e Salim (2010), que foi realizado com uma amostra de 374 empresas na Malásia, no qual encontraram que 15,8\% das empresas pesquisadas definiram os segmentos operacionais do ponto de vista geográfico, enquanto $84,2 \%$ definiram por linha de negócios, e também pela pesquisa de Nichols e Street (2007), que estudou as características de divulgação de segmentos em 160 companhias de diversos países. Os resultados mostram que os gestores utilizam-se da flexibilidade da norma na definição dos segmentos; as empresas divulgaram entre 1 e mais de 10 segmentos.

Diante de tal contexto, este estudo teve a seguinte questão norteadora da pesquisa: quais as características da divulgação de segmentos feita pelas companhias abertas com operação no Brasil, no ano de 2010, em especial por ser este o primeiro ano de publicação compulsória?

O estudo teve como objetivo traçar um panorama da divulgação de segmentos nas companhias abertas que operam no Brasil, a partir da análise das demonstrações financeiras publicadas no ano de 2010, identificando como foram definidos e quantos são os segmentos publicados, e analisar tais resultados em relação a características corporativas da empresa tais como tamanho, setor de atuação e status de listagem da companhia nos níveis de governança corporativa.

A pesquisa apresentada é oportuna e tende a contribuir para o desenvolvimento do tema no Brasil, ao mostrar quais as práticas das companhias abordadas na divulgação de seus segmentos operacionais, as quantidades apresentadas de segmentos, como as empresas estão segmentadas e se é possível deter- 
minar padrão de segmentação de acordo com características específicas das empresas. Destaca-se que os resultados de 2010, publicados em 2011, representam a primeira experiência das empresas na divulgação compulsória das informações por segmento.

Estudos anteriormente desenvolvidos no Brasil (Vasconselos \& Szuster, 2003; Cruz, Machado, Pereira \& Carvalho, 2011 e Schvirck \& Gasparetto, 2011) abordaram o tema a partir da evidenciação voluntária dos dados e encontraram poucos dados sobre segmentos nas empresas pesquisadas. Julga-se relevante conhecer, no momento em que a divulgação passa a ser compulsória, de que forma as companhias abertas estão dispondo os dados aos seus stakeholders.

\section{Referencial teórico}

\subsection{Evidenciação de informações contábeis}

Os relatórios gerados pela contabilidade a partir do registro dos fatos ocorridos nas empresas têm por objetivo principal prestar, aos interessados, informações sobre a situação econômica e financeira, bem como os riscos e retornos relacionados ao investimento. A discussão sobre usuários da informação contábil já foi realizada por diversos autores. Entre eles, Iudícibus (2004, p. 23) apresenta a Figura1, na qual relaciona os principais clientes e suas aspirações com a informação gerada pela contabilidade.

\begin{tabular}{|ll|}
\hline Usuário da informação contábil & Meta que desejaria maximizar ou tipo de informação mais importante \\
\hline Acionista minoritário & Fluxo regular de dividendos. \\
\hline $\begin{array}{l}\text { Acionista majoritário ou com grande } \\
\text { participação }\end{array}$ & Fluxo de dividendos, valor de mercado da ação, lucro por ação. \\
\hline Acionista preferencial & Fluxo de dividendos mínimos ou fixos. \\
\hline Emprestadores em geral & $\begin{array}{l}\text { Geração de fluxos de caixa futuros, suficientes para receber de volta o capital } \\
\text { mais os juros, com segurança. }\end{array}$ \\
\hline Entidades governamentais & Valor adicionado, produtividade, lucro tributável. \\
\hline $\begin{array}{l}\text { Empregados em geral, como } \\
\text { assalariados }\end{array}$ & $\begin{array}{l}\text { Fluxo de caixa futuro capaz de assegurar bons aumentos ou manutenção de } \\
\text { salários, com segurança; liquidez. }\end{array}$ \\
\hline Média e alta administração & $\begin{array}{l}\text { Retorno sobre o ativo, retorno sobre o patrimônio líquido; situação de } \\
\text { liquidez e endividamento confortáveis. }\end{array}$ \\
\hline
\end{tabular}

Figura 1. Usuários da informaç̧ão contábil

Fonte: Iudícibus (2004)

Lopes (2002, p. 7) acrescenta que o mercado financeiro "é um dos maiores usuários da informação contábil por intermédio de analistas, corretoras, investidores institucionais e individuais, bancos de investimentos, etc." Sejam quais forem os interesses dos usuários nas empresas, as decisões que devem tomar necessitam de informações sobre os dados corporativos, sejam financeiros, econômicos ou operacionais. Nesse contexto, a evidenciação de informações é fundamental para o conhecimento dos usuários sobre a empresa.

A evidenciação da informação contábil, de acordo com Iudícibus (2004, p. 121), "está ligada aos objetivos da contabilidade, ao garantir informações diferenciadas para os vários tipos de usuários". Enquanto que para Hendriksen e Van Breda (1999, p. 515), a evidenciação tem por objetivo "dar informação importante e relevante aos usuários [...] para ajudá-los a tomar decisões da melhor maneira possível." Argumentam os autores que "a quantidade de informação a ser divulgada depende, em parte, da sofisticação de quem a recebe". Nesse sentido, Iudícibus (2004, p. 21) defende que o objetivo da contabilidade é construir "um arquivo básico da informação contábil" no qual cada tipo de usuário, de forma flexível, possa obter a informação que lhe é conveniente. 
No entanto, o dinamismo dos fatos corporativos não possibilita que a contabilidade evidencie tudo o que ocorre nas empresas e, dessa forma, Lopes e Martins (2005, p. 55) argumentam que a contabilidade é empregada pelos gestores para comunicar de forma seletiva os aspectos mais interessantes da empresa. Essa comunicação é seletiva porque os gestores não fornecem todas as informações ao seu dispor, mas selecionam o que é mais relevante ao seu próprio interesse.

As escolhas das informações publicáveis são realizadas, especialmente, de forma a atender às exigências legais e, segundo Paulo (2007, p. 30), são conduzidas por um amplo conjunto de fatores que afetam os números e algumas destas escolhas possuem efeitos imediatos e/ou de longo prazo nos resultados, outras afetam somente o resultado dentro do período.

Verrecchia (2001, p. 99), ao apresentar a evidenciação baseada na discricionariedade, argumenta que este é um evento endógeno por considerar os incentivos que os gestores e/ou empresas possuem para divulgar informações que eles conhecem. Essa decisão, tipicamente, é tomada no contexto do mercado de capitais, um significativo consumidor da informação divulgada, ou seja, as empresas tendem a divulgar as informações de acordo com os benefícios que podem extrair delas.

Os órgãos reguladores do mercado, e também os investidores e financiadores, buscam melhorar a evidenciação de informações das companhias. Os investidores e financiadores oferecem mais recursos às empresas que têm mais transparência em seus atos, e as entidades reguladoras por meio de normas $\mathrm{e}$ leis. Nesse sentido, a harmonização das normas contábeis brasileiras às normas internacionais de contabilidade motivou diversas alterações nas práticas das empresas em relação à forma de contabilização e de divulgação das informações.

A partir do exercício de 2010, com divulgação de relatórios no início de 2011, as empresas que negociam valores mobiliários no mercado financeiro passaram a ter que divulgar, juntamente com as demonstrações contábeis já existentes, as informações por segmentos, de acordo com o pronunciamento CPC 22. Com essa prática, a empresa deve divulgar informações que permitam aos usuários das demonstrações contábeis avaliarem a natureza e os efeitos financeiros das atividades de negócios nos quais ela está envolvida e os ambientes econômicos em que opera.

A vigência deste pronunciamento tende a proporcionar aos stakeholders da empresa uma visão mais detalhada dos negócios operados pela companhia. Como exposto por Torres (2011), os acionistas e analistas têm agora informações que até então a maioria das empresas não divulgavam: o lucro obtido em cada segmento operacional.

\subsection{Relatórios por segmentos}

As fusões e a internacionalização das empresas e a ampliação de mercados de atuação formaram grupos corporativos que atuam em diversas áreas geográficas e em distintos negócios. As holdings de companhias abertas, normalmente, gerenciam as atividades desses conglomerados de forma consolidada, ou seja, todos os negócios estão agrupados em uma única companhia controladora. Dessa forma, informações que podem ser relevantes para o agente interessado na empresa ficam agrupadas com diversos outros dados, sendo apresentadas de forma consolidada ao mercado.

No intuito de ter informações com maior grau de detalhamento, a aplicação do CPC 22, baseado no IFRS 8, busca mostrar ao mercado como as empresas atuam em cada um dos segmentos, proporcionando aos stakeholders conhecerem os riscos e as possibilidades inerentes a cada ramo de atuação.

Para Iudícibus et al. (2010, p. 628),

o princípio básico é que as informações apresentadas por segmentos, em conjunto com as demonstrações contábeis, possibilitem aos usuários a avaliação correta da natureza das atividades do negócio e seus respectivos efeitos financeiros, conhecendo de fato o ambiente econômico em que a empresa está inserida. 
Garrison, Noreen e Brewer (2007, p. 446) definem um segmento como uma parte ou atividade da organização a respeito da qual os administradores gostariam de ter dados de custo, receita ou lucro. Para o CPC 22, item 5, um segmento operacional é um componente da entidade que desenvolve atividades de negócios das quais pode obter receitas e incorrer em despesas, cujos resultados são regularmente revistos no processo de tomada de decisões e avaliação de desempenho e, também, onde seja possível individualizar a informação financeira disponível.

Iudícibus et al. (2010, p. 628) defendem que a separação por segmento é importante para que seja possível compreender o histórico e as tendências da companhia, entender o contexto regional de um produto ou serviço, avaliar a influência de aspectos políticos, mensurar a contribuição de um cliente relevante para as receitas da empresa, entre outras possibilidades que se criam com os relatórios por segmento.

Nesse sentido, Vasconselos e Szuster (2003, p. 72) comentam que

a informação por segmentos de negócios assume crescente importância na análise econômico-financeira das empresas nacionais e internacionais aprimorando sua evidenciação, e do ponto de vista gerencial é de grande ajuda na tomada de decisão. Do ponto de vista do usuário externo, aumenta a transparência da empresa, uma vez que informa ao mercado a estratégia adotada em suas atividades.

Até a aplicação do CPC 22, houve no Brasil pouco incentivo para divulgação de informações por segmento, conforme exposto por Iudícibus et al. (2010, p. 627). Porém algumas empresas faziam, de forma voluntária, ou por exigência da atuação em mercados internacionais, esse tipo de divulgação, porém de forma tímida e incipiente.

O tema relatórios por segmentos é recente no Brasil. No entanto, normas internacionais já prescrevem tais procedimentos há algum tempo. Em novembro de 2006, o International Accounting Standards Board - (IASB) emitiu a IFRS 8, que substituiu a International Accounting Standard 14 (IAS 14), que havia sido emitido em 1981 e passado por atualizações até ser substituído em 2006. No ambiente regulamentado pelo Financial Accounting Standards Board (FASB), em junho de 1997, foi editada a última versão da norma que trata do tema, o Statement Financial Accounting Standard 131 (SFAS 131), que substituiu o SFAS 14 de 1976.

Na legislação brasileira, a partir do exercício 2010, as informações por segmento passaram a ser exigidas e, conforme apresentado pelo estudo de Vasconselos e Szuster (2003, p.86), a inexistência de uma norma explícita sobre a apresentação dessas informações no mercado brasileiro fazia, antes da vigência do CPC 22, com que as companhias publicassem-nas no exterior, pela normatização do IASB ou do FASB e, não, no mercado interno.

Vasconselos e Szuster (2003) realizaram, no ano de 2002, estudo em 30 empresas listadas na Bovespa, com base nos dados publicados no exercício de 2001, para avaliar a qualidade da evidenciação voluntária de informações contábeis por segmentos no Brasil, por empresas com emissão de títulos no mercado internacional, onde deviam evidenciar informações por segmentos por força da IAS 14. No grupo de empresas estudado, 57\% apresentaram informações por segmento no relatório de administração e 17\% em notas explicativas. Os autores também destacam que $26 \%$ das companhias não apresentaram nenhum tipo de informação relacionada a segmentos no mercado brasileiro.

Vasconselos e Szuster (2003, p. 85) concluíram que não foi possível confirmar que empresas que emitem títulos no exterior apresentam melhores informações no mercado nacional, ou seja, a falta de legislação exigindo a publicação fazia com que as empresas publicassem as informações no mercado externo e, não, no Brasil.

A divulgação de informações por segmento no Brasil, de forma voluntária, foi objeto de estudo de Cruz et al. (2011), com o objetivo de verificar como as empresas divulgaram informações por segmentos referentes ao exercício 2009. A pesquisa foi aplicada em 106 companhias listadas na BM\&FBovespa (2012) e encontrou que somente $13,2 \%$ das empresas estudadas apresentaram, voluntariamente, informações por segmento. Cruz et al. (2011, p.16) concluem que, em linhas gerais, a divulgação por segmento ainda é incipiente no cenário brasileiro. 
Corroborando com esses resultados, o estudo de Schvirck e Gasparetto (2011), desenvolvido com 49 empresas listadas na BM\&FBovespa (2012), investigou a relação da divulgação voluntária de informações por segmentos, no ano de 2009, com os níveis de governança corporativa. Os resultados apontaram que as empresas que aderem ao mais elevado padrão de governança têm maior disposição a divulgar voluntariamente as informações por segmento, no entanto, todas as companhias demonstraram baixo nível de aderência às exigências do CPC 22.

Dentre os possíveis motivos para a pouca divulgação voluntária, além da questão de não existir uma norma exigindo-a, pode ser citado o receio com tal divulgação. Talha, Sallehhuddin e Mohammad (2006, p. 266) explicam que um dos principais argumentos é que o alto custo de preparação da informação excede o potencial benefício. Além disso, os autores apresentam como argumento mais sério contra a publicação de informações por segmento o fato de beneficiar potenciais concorrentes com informações estratégicas da companhia.

Nesse contexto, Talha et al. (2006) realizaram pesquisa com 116 companhias listadas na Bolsa da Malásia, no período de 2000 a 2002, com o objetivo de avaliar, empiricamente, a mudança de padrão da vantagem competitiva nas empresas após a publicação de informações por segmento. Os resultados indicam que o nível de competitividade ou o desempenho financeiro das companhias aumenta quando a qualidade da evidenciação de segmentos diminui, ou seja, quando as empresas divulgam informações com maior qualidade, tende a diminuir seu nível de competitividade, medido pelo desempenho financeiro. Ao considerar o tamanho das empresas, o estudo aponta que, dado o mesmo nível de qualidade na divulgação, as empresas grandes apresentam níveis de competitividade piores do que as empresas menores, isto é, as maiores empresas estão mais expostas à desvantagem competitiva do que as companhias menores.

Edwards e Smith (1996) avaliaram a existência de desvantagem competitiva pela divulgação de informações segmentadas em empresas do Reino Unido. O estudo apontou evidências de maior desvantagem competitiva de empresas que divulgam relatórios segmentados por região geográfica em relação às que divulgam os relatórios por segmentos de negócios.

Na Malásia, Talha e Salim (2010) realizaram estudo com 374 empresas listadas na bolsa local, com o objetivo de pesquisar os fatores que levam as empresas a escolher entre segmento de negócios ou geográfico como segmento primário. A pesquisa utilizou os dados referentes ao exercício 2006 e encontrou evidências de que tamanho, desempenho financeiro e setor industrial têm impacto significativo na escolha do segmento primário como segmento de negócios em detrimento da informação geográfica.

Em outro estudo, Jahmani (2003) encontrou que a evidenciação de segmento de negócios e informações de segmentos geográficos têm impacto sobre a percepção de risco da firma. As demonstrações consolidadas das firmas não prestam informações suficientes ao investidor para a decisão de investimentos apropriada, e os dados por linha de negócio ou dados geográficos são informações valiosas que complementam as demonstrações consolidadas.

Ettredge, Kwon e Smith (2002) avaliaram os efeitos associados à utilização do SFAS 131 no mercado de capitais dos Estados Unidos, constantando que a adoção de tal norma teve impacto significativo sobre as empresas que anteriormente tinham maior incentivo para agregar informações por segmento. Com a utilização da abordagem gerencial, as empresas passaram a divulgar informações menos agregadas por linhas de produtos, o que, para os autores, melhorou a evidenciação das empresas.

No Brasil, a Ernst Young Terco, juntamente com a Fipecafi, desenvolveram, em 2011, estudo em 56 empresas com o intuito de avaliar a aplicação do CPC 22 a partir dos demonstrativos de 2010. Os resultados mostraram que as companhias divugaram entre um e nove segmentos - destaque para o expressivo número de empresas (23\%) que apresentaram somente um segmento. Quanto à definição dos segmentos, $61 \%$ foram por linha de produto, $7 \%$ por área geográfica e $32 \%$ utilizaram ambos os critérios.

Garrison et al. (2007 p. 446) esclarecem que segmentos podem ser divisões de uma empresa, território de vendas, lojas individuais, centros de serviço, fábricas, departamentos de marketing, clientes individuais e linhas de produtos. As operações de uma empresa podem ser segmentadas de muitas maneiras. 
Pahler (2003, p. 458), à luz do que determina o SFAS 131, argumenta que, conceitualmente, informações por segmento podem ser apresentadas sob diversas formas, por exemplo: por produtos e serviços, por área geográfica, por instituição legal, por tipo de cliente, ou pela forma como a empresa organiza internamente os segmentos (por subsidiárias, divisões, departamentos ou outras unidades internas), para relatar a forma utilizada pela gestão para a tomada de decisões. Ressalta o autor que a última forma, a abordagem gerencial, é a requerida pelo SFAS 131 e também pelo IFRS 8 .

Instituído a partir do IFRS 8, as informações de acordo com o CPC 22 devem ser relatadas, utilizando-se da abordagem gerencial, ou seja, tais informações devem ser reportadas na mesma base usada internamente para avaliar o desempenho dos segmentos operacionais e também para o processo decisório na alocação de recursos. Conforme descrito no item 25 do pronunciamento,

o montante de cada item dos segmentos divulgados deve corresponder ao valor reportado ao principal gestor das operações para fins de tomada de decisão sobre a alocação de recursos ao segmento e de avaliação do seu desempenho.

A abordagem gerencial proposta pela norma foi alvo de críticas em alguns estudos, como, por exemplo, Crawford, Helliar e Power (2010), que mencionam que os investidores estão preocupados, em relação ao IFRS 8, com a possibilidade de haver manipulação de dados, devido à liberdade no processo de evidenciação das informações por segmentos, uma vez que a norma requer a divulgação de informações que tenham sido preparadas e mensuradas para decisões gerenciais internas, sem clara discussão de quem é o gestor de operações, o qual é importante agente na definição dos segmentos da empresa. Determina divulgação de segmentos geográficos, mas permite que essas informações não sejam divulgadas se a empresa não as prepara para propósitos internos, ou seja, atribuindo à discricionariedade dos gestores à forma e ao conteúdo a ser divulgado.

Na definição dos segmentos divulgáveis, é possível que sejam identificados fatores que possibilitem a agregação dos valores, conforme exposto no item 12 do CPC 22,

dois ou mais segmentos operacionais podem ser agregados em um único segmento operacional [...] se tiverem características econômicas semelhantes e se forem semelhantes em relação a cada um dos seguintes aspectos:

- natureza dos produtos ou serviços;

- natureza dos processos de produção;

- tipo ou categoria de clientes dos seus produtos e serviços;

- métodos usados para distribuir os seus produtos ou prestar os serviços; e

- se aplicável, a natureza do ambiente regulatório, por exemplo, bancos, seguros ou serviços de utilidade pública.

A norma contábil prevê que, quando identificados os segmentos, eles sejam submetidos a testes quantitativos para decidir se são divulgáveis ou não. Dessa forma, conforme item 13 do CPC 22, serão divulgáveis os segmentos que atenderem a qualquer um dos seguintes critérios:

a) quando a receita auferida pelo segmento é igual ou superior a $10 \%$ da receita de todos os segmentos operacionais;

b) quando o lucro ou prejuízo apurado é igual ou superior a $10 \%$ do maior dos seguintes montantes:

i. lucro apurado de todos os segmentos que não apresentaram prejuízos, e

ii. prejuízo apurado de todos os segmentos operacionais que apresentaram prejuízos.

c) quando os ativos do segmento representarem $10 \%$ ou mais dos ativos combinados de todos os segmentos. 
Conforme item 19 do CPC 22, se o número de segmentos divulgáveis “[...] for superior a 10, a entidade deve ponderar se o limite prático já não tenha sido atingido". A partir de tal determinação, observa-se que, mesmo que seja utilizada a abordagem gerencial na elaboração do relatório por segmento, o tomador de decisões, internamente à empresa, tem acesso a diversas outras informações que lhe dão suporte, ou seja, os relatórios por segmento tendem a ter mais informações do que os consolidados, mas ainda não possuem o mesmo detalhamento de uma informação utilizada internamente.

Nesse contexto, a divulgação de informações de resultados por segmento pode assumir diversas formas e estruturas, pois ao utilizar a abordagem gerencial, na divulgação, a estruturação de informações pode ser muito diferente de uma empresa para outra.

\section{Procedimentos Metodológicos}

A pesquisa tem foco descritivo por apresentar as características da publicação dos segmentos divulgados pelas companhias constantes na amostra. Gil (2002, p. 43) explica que as pesquisas descritivas têm como objetivo primordial a descrição das características de determinada população ou fenômeno ou, então, o estabelecimento de relações entre variáveis.

Quanto aos procedimentos técnicos, esta pesquisa apresenta-se como estudo bibliográfico que é desenvolvido com base em material já elaborado, constituído principalmente de livros e artigos científicos, como definido por Gil (2002, p. 44), e também como uma pesquisa documental por utilizar-se, como explicam Martins e Theóphilo (2007, p. 55), de documentos como fonte de dados, informações e evidências.

A amostra utilizada para o desenvolvimento da pesquisa foi definida pela acessibilidade aos dados necessários. Foram selecionadas dentre as 300 maiores empresas listadas na edição 2010 da Revista Exame Melhores e Maiores as companhias abertas com demonstrações publicadas no site da BM\&FBovespa (2012). Dessa forma, o grupo para o estudo foi formado por 81 empresas.

Dessas empresas, foram verificadas as notas explicativas, nas quais se buscou pesquisar como foram divulgados os segmentos. Os dados do estudo referem-se ao exercício 2010. Caracterizada a publicação dos relatórios por segmentos, testou-se se as variáveis relacionadas às características corporativas da empresa, tamanho, status de listagem na Bolsa de Valores e setor de atuação mantinham algum tipo de correlação com a quantidade de segmentos divulgada.

Os resultados foram analisados com a utilização de estatística descritiva, definida por Martins (2002, p. 19) como a organização, sumarização e descrição de um conjunto de dados. Nesse sentido, os dados da pesquisa foram agrupados e categorizados de forma a caracterizar os elementos de análise e ainda fez-se a avaliação da correlação entre as variáveis de estudo com o intuito de entender os relacionamentos existentes entre elas. Os dados foram tratados estatisticamente com o auxílio do software SPSS 13.0.

\section{Apresentação e Análise dos Resultados}

O estudo buscou apresentar um panorama da divulgação de segmentos, exigido pelo CPC 22 para as demonstrações financeiras a partir do exercício de 2010, sem o objetivo de avaliar a qualidade das informações divulgadas, mas, sim, como as empresas definiram e quantos segmentos divulgaram. Entende-se, no entanto, que, ao apresentar dados de forma mais detalhada, em mais segmentos, a empresa tende a prestar melhor informação ao seu usuário. Dessa forma, há a expectativa de que a companhia que divulga mais segmentos amplie o nível de entendimento do seu usuário quanto ao contexto de atuação.

Para operacionalizar a pesquisa, foram analisadas demonstrações contábeis de 81 companhias abertas com atuação no mercado brasileiro. Nesse grupo, 13,5\% das empresas não apresentaram nenhuma referência a segmentos em suas notas explicativas, estando, dessa forma, em desacordo com o pronunciamento CPC 22. Essas empresas foram excluídas das análises subsequentes por não apresentarem dados a 
serem utilizados no estudo. Desta forma, a amostra final com informações expressas sobre segmentos é composta por 70 companhias.

A adoção da abordagem gerencial na publicação de informações por segmento, conforme prescrito nas normas, possibilita escolhas que podem imprimir diferenças na estrutura das demonstrações divulgadas, pois, conforme argumentam Talha et al. (2006, p. 272), existem julgamentos discricionários dos gestores ao determinarem como definir os segmentos, quais itens são divulgados e o nível de materialidade comprometido.

Nesse contexto, a primeira avaliação realizada foi sobre como as empresas definiram seus segmentos. Das empresas que divulgaram segmentos, $11 \%$ utilizaram como critério para a definição deles, a atuação geográfica. Em 86\% dos casos, o segmento foi definido por linha de produtos ou serviços, ou seja, por linha de negócios e em 3\% das empresas houve a classificação tanto por atuação geográfica quanto por linha de negócios, conforme apresentado na Figura 1.

Destaca-se a convergência desta pesquisa com o estudo realizado pela Ernst Young Terco e Fipecafi (2011), no sentido da predominância da definição dos segmentos por linha de negócios. No entanto, devido à diferença no grupo de empresas estudadas, não apresentou coincidências nos percentuais encontrados.

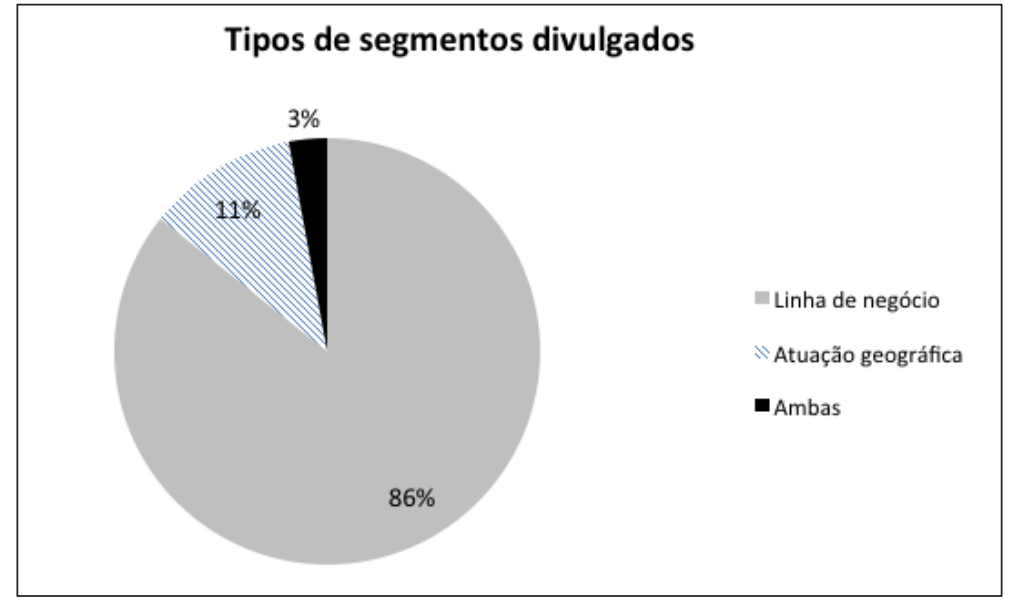

Figura 1. Tipos de segmentos divulgados pelas empresas

Estudos relatam que a utilização do SFAS 131 e do IFRS 8, em substituição às normas anteriores, proporcionou melhoria nas informações prestadas pelas empresas pela desagregação de linhas de produtos e também pelo aumento no número de segmentos divulgados (Berger \& Hann, 2003; Street, Nichols \& Gray, 2000; Ettredge, Kwon, Smith \& Stone, 2006; Nichols \& Street, 2007; Mardini, Crawford \& Power, 2012). No mercado brasileiro, as empresas divulgaram entre um e oito segmentos. A Tabela 1 resume os achados da pesquisa quanto ao número de segmentos publicados.

Tabela 1

Número de segmentos divulgados

\begin{tabular}{cc}
\hline Número de segmentos & \% de empresas da amostra \\
\hline Um segmento & $27,1 \%$ \\
\hline Dois segmentos & $22,9 \%$ \\
\hline Três segmentos & $20,0 \%$ \\
\hline Quatro segmentos & $17,1 \%$ \\
\hline Cinco segmentos & $5,7 \%$ \\
\hline Seis segmentos & $4,3 \%$ \\
\hline Sete segmentos & $1,4 \%$ \\
\hline Oito segmentos & $1,4 \%$ \\
\hline
\end{tabular}


Com base nos dados da Tabela 1, nota-se que há pouca segmentação nas companhias analisadas. Percebe-se que 27,1\% delas apresentaram suas informações de forma consolidada, sob o argumento de que as informações foram passadas ao tomador de decisões dessa forma, ou ainda porque a atividade da empresa está centralizada em somente uma linha de negócios identificável.

$\mathrm{Na}$ amostra estudada, $42,9 \%$ das empresas estão situadas nos grupos de dois e três segmentos, sendo que um dos segmentos, normalmente, é o corporativo, ou seja, não é um segmento operacional, mas, sim, de estrutura administrativa.

Os resultados demonstrados na Tabela 1 apresentam relação com os achados do estudo da Ernst Young Terco e Fipecafi (2010), em especial na concentração de empresas que divulgaram entre dois e quatro segmentos, bem como o percentual considerável de empresas que apresentaram os dados em segmento único.

O ramo de atuação da companhia pode influenciar o formato de divulgação dos relatórios. Talha e Salim (2010, p.22) argumentam que o nível de evidenciação difere de acordo com o setor, ou seja, cada setor tem suas próprias características e regulamentações. Nesse sentido, a Tabela 2 demonstra a característica de divulgação dos relatórios por segmento de acordo com os setores de atuação das empresas constantes da amostra. Ressalta-se que o baixo número de empresas em cada setor não possibilitou aprofundar a discussão deste item.

Tabela 2

Forma de definição de segmentos segregada por setores

\begin{tabular}{|c|c|c|c|c|}
\hline \multirow{2}{*}{ Setor } & \multicolumn{3}{|c|}{ Definição do segmento } & \multirow[t]{2}{*}{$\begin{array}{l}\text { Número de } \\
\text { segmentos }\end{array}$} \\
\hline & Geográfico & Linha de negócios & Ambos & \\
\hline Atacado & & 1 & & 1 \\
\hline Autoindústria & & 3 & & 2 a 5 \\
\hline Bens de capital & 1 & & & 2 \\
\hline Bens de consumo & 3 & 3 & 1 & 2 a 4 \\
\hline Energia & & 20 & & 1 a 8 \\
\hline Indústria da construção & 1 & 1 & & 2 e 4 \\
\hline Indústria digital & & 2 & & 2 e 4 \\
\hline Mineração & & 1 & & 5 \\
\hline Papel e celulose & & 3 & & 2 e 3 \\
\hline Produção agropecuária & & & 1 & 2 \\
\hline Química e petroquímica & & 3 & & 2 e 6 \\
\hline Serviços & & 6 & & 1 a 4 \\
\hline Siderurgia e metalurgia & 1 & 2 & & 4 e 5 \\
\hline Telecomunicações & 1 & 6 & & 1 e 3 \\
\hline Têxtil & 1 & 1 & & 1 e 3 \\
\hline Transportes & & 3 & & 1 e 2 \\
\hline Varejo & & 5 & & 1 a 4 \\
\hline TOTAL & 8 & 60 & 2 & \\
\hline
\end{tabular}

Destaca-se na Tabela 2 o setor de bens de consumo, onde se observou a maior incidência da definição por atuação geográfica - $43 \%$ das empresas. Tal informação refere-se a resultados apurados no mercado nacional e também na atuação internacional das companhias. Pode-se inferir que, por ser um setor que tende a atuar com grande diversidade de produtos, é mais relevante a informação por área geográfica de abrangência do que por linha de negócios. 
No setor de energia todas as empresas estudadas definiram segmentos por linha de negócios. A diferença na quantidade de segmentos pode ser destacada, pois, assim como houve empresa que divulgou somente um segmento, houve também empresa que publicou oito segmentos, mostrando que não é possível estabelecer um padrão entre as companhias.

Segundo Talha e Salim (2010, p. 21), o status de listagem da companhia também pode influenciar a evidenciação. No mercado brasileiro, as companhias podem ser listadas em quatro segmentos diferenciados, de acordo com o padrão utilizado na Bolsa de Valores. O Novo Mercado é o nível mais elevado, posteriormente, Nível 2, Nível 1 e as empresas que não aderiram a nenhum dos níveis, o que se denominou Mercado Tradicional. A tendência é de que as empresas dos níveis de governança mais elevados tenham maior disposição à evidenciação, logo terão mais segmentos e com informações divulgadas sob diferentes critérios na definição do segmento. Conforme indicam os resultados da pesquisa de Murcia e Santos (2009, p. 12), a governança corporativa é um dos fatores que pode explicar o nível de evidenciação.

Diante disso, observaram-se as características da divulgação por segmento, buscando identificar o comportamento das empresas, segregadas pelo seu nível de listagem no mercado. A Tabela 3 apresenta o resumo desta análise.

Tabela 3

Forma de definição de segmentos segregada por nível de governança corporativa da Bovespa

\begin{tabular}{|c|c|c|c|c|}
\hline \multirow{2}{*}{ Setor } & \multicolumn{3}{|c|}{ Definição do segmento } & \multirow{2}{*}{$\begin{array}{l}\text { Quantidade de } \\
\text { segmentos }\end{array}$} \\
\hline & Geográfico & Linha de negócios & Ambos & \\
\hline Novo Mercado & $12,5 \%$ & $79,2 \%$ & $8,3 \%$ & 1 a 5 \\
\hline Nível 2 & & $100 \%$ & & 1 a 4 \\
\hline Nível 1 & $15,4 \%$ & $84,6 \%$ & & 1 a 6 \\
\hline Mercado Tradicional & $10,3 \%$ & $89,7 \%$ & & 1 a 8 \\
\hline
\end{tabular}

Os dados apurados na pesquisa mostram que o nível de listagem não apresentou relevância na definição de características da divulgação. Cabe destacar, no entanto, o fato de que somente empresas do Novo Mercado divulgaram segmentos tanto por linha de negócios quanto por região geográfica. No Novo Mercado, 41,7\% das empresas divulgaram dois segmentos operacionais, 25\% divulgaram somente um segmento em suas atividades e 20,8\% divulgaram quatro segmentos. Quanto às empresas do mercado tradicional, 34,5\% divulgaram apenas um segmento e $31 \%$ divulgaram três segmentos operacionais de atuação.

A avaliação do tamanho da empresa é um fator citado em diversos estudos como relevante na influência sobre a evidenciação contábil. Entre eles, no Brasil, Cunha e Ribeiro (2008), Salotti e Yamamoto (2006) e Murcia e Santos (2009) encontraram, em suas pesquisas, significância na relação entre o tamanho da companhia e a evidenciação.

Contribuindo com a discussão, Silva (2008, p. 54) apresenta diversas medidas contábeis utilizadas como proxy de tamanho de empresas. Na pesquisa realizada por Silva (2008), em estudos sobre evidenciação, foram utilizados como medidas de tamanho a receita e o ativo total.

Neste estudo, utilizou-se o valor do ativo total como critério para tamanho da companhia. A amostra foi estratificada por meio da definição de quartis a partir do valor do ativo total das empresas constantes no estudo. Desse modo, o primeiro quartil agrupou as menores empresas do estudo e o último as companhias com os maiores valores de ativo total. Os dados referentes às características do relatório por segmento de acordo com o tamanho das empresas estão apresentados na Tabela 4. 
Tabela 4

Forma de definição de segmentos segregada pelo tamanho da empresa

\begin{tabular}{lcccc}
\multicolumn{1}{c}{ Tamanho } & \multicolumn{2}{c}{ Definição do segmento } & \multirow{2}{*}{$\begin{array}{c}\text { Quantidade de } \\
\text { segmentos }\end{array}$} \\
\cline { 1 - 3 } Ativo total em $\mathrm{R} \$$ milhões & Geográfico & Linha de negócios & Ambos & 1 a 7 \\
\hline Até $\mathrm{R} \$ 3.336$ & $11,1 \%$ & $88,9 \%$ & & 1 a 8 \\
\hline Entre $\mathrm{R} \$ 3.336$ e $\mathrm{R} \$ 7.753$ & $11,8 \%$ & $88,2 \%$ & & 1 a 5 \\
\hline Entre $\mathrm{R} \$ 7.753$ e $\mathrm{R} \$ 22.625$ & & $94,1 \%$ & $5,9 \%$ & 1 a 6 \\
\hline Maior do que $\mathrm{R} \$ 22.625$ & $22,2 \%$ & $72,2 \%$ & $5,6 \%$ & \\
\hline
\end{tabular}

Percebe-se, na Tabela 4, que em todos os grupos a definição de segmentos por linha de negócios é predominante. Somente nos grupos três e quatro, onde estão as maiores empresas, é que se nota a divulgação de ambos os tipos de segmento.

No primeiro grupo, que envolve as menores empresas, foram divulgados relatórios apresentando entre um e sete segmentos. Destaca-se que $38,8 \%$ apresentaram um segmento, ou seja, as companhias identificaram que há uma única linha de negócios e, portanto, não há necessidade de apresentar relatório à parte sobre segmentos. Em 27,8\% das empresas, houve a apresentação de dois segmentos; 16,7\% divulgaram três segmentos; $11,1 \%$, quatro segmentos; e 5,6\% publicaram sete segmentos distintos.

No segundo quartil, 35,2\% das empresas apresentaram somente um segmento, 29,4\% divulgaram dois segmentos, $11,8 \%$ publicaram três e quatro segmentos e $5,9 \%$ apresentaram seis e oito segmentos de negócios.

O terceiro grupo também apresentou a maioria das empresas $(29,4 \%$,$) com apenas um segmento;$ $17,7 \%$ apresentaram dois e quatro segmentos; em $23,5 \%$ dos casos, as empresas publicaram três segmentos; e $11,7 \%$ divulgaram cinco segmentos operacionais.

O grupo das maiores empresas foi o que apresentou maior segmentação. Somente 5,5\% divulgaram apenas um segmento; $16,7 \%$ publicaram dois segmentos; $27,8 \%$ divulgaram três e quatro segmentos de negócios; e 11,1\% das empresas segmentaram seus negócios em cinco e seis segmentos.

Em síntese, no que se refere ao tamanho das companhias, foi possível identificar a tendência de que as maiores empresas divulguem relatórios com maior segmentação para a tomada de decisões, já que no, grupo de maiores ativos, 77,8\% delas apresentaram entre três e seis segmentos, enquanto que nos dois grupos de menores ativos, em torno de $65 \%$ das empresas divulgaram um segmento operacional ou divulgaram até dois segmentos.

A análise de correlações entre as variáveis corrobora os dados avaliados pelas proporções anteriormente descritas. Na Tabela 5 percebe-se que somente o tamanho do ativo das companhias apresentou relação significante com as características relacionadas aos segmentos, tipo e quantidade. Assim, entende-se que quanto maior for a empresa, mais segmentos ela tende a divulgar e também utilizar mais de um critério para a definição do segmento divulgável. 
Tabela 5

Correlação entre as variáveis

\begin{tabular}{|c|c|c|c|c|c|c|}
\hline & \\
\hline & & $\begin{array}{l}\text { Quantidade } \\
\text { de segmentos }\end{array}$ & $\begin{array}{l}\text { Tipo de } \\
\text { segmento }\end{array}$ & $\begin{array}{l}\text { Setor de } \\
\text { atuação }\end{array}$ & $\begin{array}{l}\text { Nível de } \\
\text { Gov. Corp. }\end{array}$ & $\begin{array}{l}\text { Ativo } \\
\text { Total }\end{array}$ \\
\hline \multirow{2}{*}{$\begin{array}{l}\text { Quantidade } \\
\text { de segmentos }\end{array}$} & \multirow{2}{*}{$\begin{array}{l}\text { Correlação de Pearson } \\
\text { Sig. (2-tailed) }\end{array}$} & \multirow{2}{*}{1} & 0,074 & $-0,160$ & $-0,111$ & $0,295^{*}$ \\
\hline & & & 0,544 & 0,186 & 0,362 & 0,013 \\
\hline \multirow{2}{*}{$\begin{array}{l}\text { Tipo de } \\
\text { segmento }\end{array}$} & Correlação de Pearson & 0,074 & \multirow{2}{*}{1} & $-0,096$ & $-0,181$ & $0,263^{*}$ \\
\hline & Sig. (2-tailed) & 0,544 & & 0,431 & 0,133 & 0,028 \\
\hline \multirow{2}{*}{$\begin{array}{l}\text { Setor de } \\
\text { atuação }\end{array}$} & Correlação de Pearson & $-0,160$ & $-0,096$ & \multirow{2}{*}{1} & 0,049 & 0,077 \\
\hline & Sig. (2-tailed) & 0,186 & 0,431 & & 0,688 & 0,526 \\
\hline \multirow{2}{*}{$\begin{array}{l}\text { Nível de Gov. } \\
\text { Corp. }\end{array}$} & Correlação de Pearson & $-0,111$ & $-0,181$ & 0,049 & \multirow{2}{*}{1} & $-0,075$ \\
\hline & Sig. (2-tailed) & 0,362 & 0,133 & 0,688 & & 0,535 \\
\hline \multirow{2}{*}{ Ativo Total } & Correlação de Pearson & $0,295^{*}$ & $0,263^{*}$ & 0,077 & $-0,075$ & \multirow[b]{2}{*}{1} \\
\hline & Sig. (2-tailed) & 0,013 & 0,028 & 0,526 & 0,535 & \\
\hline
\end{tabular}

* Correlação é significante ao nível de 0,05

\section{Considerações Finais}

A disponibilidade de informações é importante para os tomadores de decisões, sejam gestores, investidores, financiadores ou qualquer outro agente interessado em uma companhia, e sejam estes internos ou externos às organizações.

No ano de 2010, entrou em vigor no Brasil o pronunciamento CPC 22 que normatiza a publicação de informações por segmento. Diante disso, as empresas que negociam títulos e valores mobiliários devem adequar-se a tal norma, divulgando informações de resultados aos usuários externos da companhia de forma segmentada, ou seja, mais pormenorizadas do que a demonstração consolidada.

Considerando a inovação normativa instituída pelo CPC 22 e a expectativa pela ampliação de dados divulgados pelas empresas aos stakeholders a partir dos segmentos, esta pesquisa teve como objetivo traçar um panorama da divulgação de segmentos em seu primeiro ano de vigência visando responder quais as características da publicação de segmentos feita pelas companhias abertas com operação no Brasil, no ano de 2010. Para isso, analisou-se, em um grupo de 81 empresas listadas na BM\&FBovespa (2012), como elas definiram seus segmentos, quantos segmentos divulgaram e se essa divulgação apresentou algum relacionamento com características corporativas das companhias.

Os resultados do estudo demonstraram que a forma de publicação de segmentos é bastante heterogênea, não sendo possível estabelecer qualquer tipo de padrão, seja por setor de atuação, por listagem de governança corporativa ou pelo tamanho do ativo da companhia. Todavia, considerando este último atributo, nota-se que há correlação positiva e significante entre tamanho e quantidade de segmentos, o que se explica pelo aumento de complexidade administrativa de companhias maiores.

Diante da possibilidade de definir segmentos a serem divulgados de acordo com a estrutura gerencial da companhia, as empresas optaram predominantemente pela divulgação de segmentos de acordo com a linha de negócios. Em relação à quantidade da segmentação existente nas companhias, o número de segmentos divulgados variou entre um e oito.

A pesquisa demonstrou que não é possível estabelecer padrão quantitativo, independente das características corporativas, uma vez que $27,1 \%$ das empresas analisadas não divulgaram atividades segmentadas, ou seja, apresentaram apenas um segmento; $60 \%$ divulgaram entre dois e quatro segmentos operacionais; e 12,9\% entre cinco e oito segmentos, no ano de 2010.

O tamanho da companhia foi a única variável do estudo que apresentou resultados relevantes estatisticamente. As grandes empresas tendem a definir os segmentos com mais de um critério, possivelmente, por sua atuação em maiores mercados. Também neste grupo é menor o número de empresas que 
não divulgou informações por segmento, conforme os critérios do CPC 22 e, ainda, estas empresas foram as que apresentaram maior segmentação, o que pode ser explicado por serem empresas com atuação em mais ramos de negócios e também em mais mercados consumidores.

Em relação ao status de listagem nos níveis de governança corporativa, nota-se no grupo do Novo Mercado, uma tendência em nível mais significativo de evidenciação, uma vez que empresas deste grupo divulgaram segmentos tanto do ponto de vista geográfico como por linha de negócios. Por outro lado, no grupo de Mercado Tradicional, há maior incidência de companhias que não publicaram segmentos, confirmando a expectativa de maior disposição à evidenciação de companhias com melhores práticas de governança corporativa.

Os resultados da pesquisa desenvolvida possibilitaram identificar como as empresas estão estruturadas em termos de segmentos operacionais, a partir da publicação compulsória exigida pelo CPC 22, em seu primeiro ano de vigência. Essa norma vem contribuir com a melhoria da evidenciação de informações ao mercado ao exigir que as companhias abertas apresentem aos seus agentes externos informações de como é formado o resultado da empresa, considerando a participação de cada um de seus segmentos operacionais.

Por outro lado, ao dar liberdade para a companhia definir o que é divulgável, a partir dos critérios quantitativos anteriormente apresentados, e com a utilização da abordagem gerencial, cria-se uma brecha para que as companhias, de forma discricionária, assumam que toda a sua atividade está agregada em um único segmento e, com isso, não apresentem informações além do que já constava em seus demonstrativos antes da vigência do CPC 22. Entretanto, cabe destacar que a adesão ao CPC 22, pelas companhias estudadas, foi significativa, considerando que de 81 empresas da amostra somente 13,5\% não divulgaram segmentos.

Os resultados deste estudo estão limitados ao grupo de empresas pesquisado, pois, por se tratar de um grupo seletivo de companhias que figuram entre as maiores do Brasil, podem não retratar as características de empresas de menor relevância no contexto econômico.

Esta pesquisa teve como foco a análise dos critérios de definição e da quantidade de segmentos divulgados. Sugere-se, para futuras pesquisas, que seja estudado o nível de evidenciação das informações exigidas pelo CPC 22 e também que se busque entender os possíveis determinantes de maior ou menor nível de evidenciação nos segmentos divulgados.

\section{Referências}

Berger, P. G. \& Hann, R. (2003). The impact of SFAS No 131 on information and monitoring. Journal of Accounting Research. 41(2), 163-223

BM\&FBovespa (2012) . Recuperado de http://www.bmfbovespa.com.br.

CPC - Comitê de Pronunciamentos Contábeis. Pronunciamento técnico CPC 22: Informações por segmento. Recuperado em 05 novembro, 2010 de http://www.cpc.org.br.

Crawford, L., Heliar, C. \& Power, D. (2010). Politics or accounting principles: Why was IFRS 8 so controversial? Centre for Business Performance - ICAEW, London.

Cruz, A. P. C, Machado, E. A., Pereira, A. F \& Carvalho, L. N. (2011). Empresas brasileiras do novo mercado e suas práticas de evidenciação voluntária de informações por segmento. Anais do Congresso Anpcont. Vitória, ES, Brasil, 5.

Cunha, J. V. A \& Ribeiro, M. S. (2008). Divulgação voluntária de informações de natureza social: um estudo nas empresas brasileiras. RAUSP-e Revista de Administração - eletrônica. 1(1), 2-23.

Edwards, P. \& Smith, R.A. (1996). Competitive disadvantage and voluntary disclosure; the case of segmental reporting. The British Accounting Review. 28(2), 155-172. 
Ernst Young Terco \& FIPECAFI. (2011). IFRS: $1^{\circ}$ Ano. Análises sobre a adoção inicial do IFRS no Brasil. Recuperado em 08 novembro, 2011 de http://mrm.comunique-se.com.br/arq/121/arq_121_219638.pdf.

Ettredge, M. L., Kwon, S. Y. \& Smith, D. (2002). Security market effects associated with SFAS N. 131: reported business segments. Review of Quantitative Finance and Accounting. 18(4), 323-344.

Ettredge, M. L., Kwon, S. Y., Smith, D. B. \& Stone, M. S. (2006). The effect of SFAS N. 131 on the cross-segment variability of profits reported by multiple segments firms. Review Accounting Studies. 11(1), 91-117.

FASB - Financial Accounting Standards Board. SFAS 131 - Disclosure about Segments of an Enterprise and Related Information. Junho/1997. 25.11.2010. Disponível em http://www.fasb.org.

Garrison, R., Noreen, E. \& Brewer, P. (2007). Contabilidade Gerencial (Tradução e revisão técnica de Antônio Zoratto Sanvicente. 11 Ed.) Rio de Janeiro: LTC.

Gil, A. C. (2002). Como elaborar projetos de pesquisa. (4 ed.) São Paulo: Atlas.

Hendriksen, E. S. \& Van Breda, M. F. (1999). Teoria da contabilidade. São Paulo: Atlas.

IASB - International Accounting Standards Board, IFRS 8: Operating Segments. Recuperado em 20 novembro, $2010 \mathrm{de}$ http://www.iasb.org.

Iudicíbus, S. (2004). Teoria da contabilidade. (7 ed.) São Paulo: Atlas.

Iudicibus, S., Martins, E.; Gelbcke, E. R. \& Santos, A. (2010). Manual de contabilidade societária - aplicável a todas as sociedades de acordo com as normas internacionais e do CPC. São Paulo. Atlas.

Jahmani, Y. (2003). The impact of segmental reporting disclosure on a firm's perceived risk. International Journal of Commerce \& Management. 13(2), pp. 102-121.

Lélis, D.L.M., Colauto, R. D., Pinheiro, L. E. T. \& Jordão, R. V. D. (2008). Evidenciação de informações financeiras: estudo empírico em empresas brasileiras dos setores de telecomunicações e consumo não cíclico. Anais do Congresso de Contabilidade e Auditoria de Portugal. Aveiro, Portugal, 12.

Lopes, A. B. (2002). A informação contábil e o mercado de capitais. São Paulo: Pioneira Thompson Learning.

Lopes, A. B. \& Martins, E. (2005). Teoria da contabilidade - uma nova abordagem. São Paulo, Atlas.

Mardini, G. H., Crawford, L., \& Power, D. M. (2012). The impact of IFRS 8 on disclosure practices of Jordanian listed companies. Journal of Accounting in Emerging Economies, 2(1), 67-90, doi: $10.1108 / 20421161211196139$

Martins, G. de A. (2002). Estatística geral e aplicada. (2 ed.) São Paulo: Atlas.

Martins, G. de A. \& Theóphilo, C. R. (2007). Metodologia da investigação científica para ciências sociais aplicadas. São Paulo. Atlas.

Murcia, F. D \& Santos, A. (2009). Fatores determinantes do nível de disclosure voluntário das companhias abertas no Brasil. Anais do Congresso IAAER - Anpcont, São Paulo, SP, Brasil, 3.

Nichols, N. B. \& Street, D. L. (2007). The relationship between competition and business segment reporting decisions under the management approach of IAS 14 Revised. Journal of International Accounting Auditing \& Taxation. 16(1), 51-68.

Pahler, A. J. (2003). Advanced Accounting - concepts and practice. (8 ed.) USA: Thomson.

Paulo, E. (2007). Manipulação das informações contábeis: uma análise teórica e empírica sobre os modelos operacionais de deteç̧ão de gerenciamento de resultados. Tese (Doutorado em Ciências Contábeis) - Programa de Pós-Graduação em Ciências Contábeis, Departamento de Contabilidade e Atuária, Faculdade de Economia, Administração e Contabilidade da Universidade de São Paulo. São Paulo.

Salotti, B. M \& Yamamoto, M. M. (2006). Divulgação voluntária da demonstração dos fluxos de caixa no mercado de capitais brasileiro. Anais do Encontro Anual da Associação Nacional dos Programas de Pós-Graduação em Administração - EnANPAD. Salvador, BA, 30. 
Schvirck, E; Gasparetto, V. (2011). Divulgação voluntária de informações por segmento e governança corporativa antes da vigência do CPC 22. Anais do Encontro Anual da Associação Nacional dos Programas de Pós-Graduação em Administração - EnANPAD. Rio de Janeiro, RJ, 35.

Silva, M. A. (2008). Aplicação de leis de potência para tratamento e classificação de tamanho de empresas: uma proposta metodológica para pesquisas contábeis. Dissertação (Mestrado em Ciências Contábeis) - Programa de Pós-Graduação em Ciências Contábeis, Departamento de Contabilidade e Atuária, Faculdade de Economia, Administração e Contabilidade de Ribeirão Preto da Universidade de São Paulo. Ribeirão Preto, SP.

Street, D., Nichols, N. \& Gray, S. (2000). Segment disclosure under SFAS No 131: Has business segment reporting improved? Accounting Horizons. 14(3), 259-285).

Talha, M. \& Salim, A. S. A. (2010) .What prompts firms to choose between business and geographic segments as a primary segment? Managerial Auditing Journal. 25(1), 17-31.

Talha, M., Sallehhuddin, A. \& Mohammad, J. (2006). Changing pattern of competitive disadvantage from disclosing financial information - A case study of segmental reporting practice in Malaysia. Managerial Auditing Journal. 21(3), 265-274.

Torres, F. (2011). Novo padrão de contabilidade obriga as empresas abertas a divulgar alguma medida de lucro por segmento de negócios, o que facilita análise dos resultados. Jornal Valor Econômico. 14.04.2011. Ed. Globo. São Paulo.

Vasconcelos, M. de G. \& Szuster, N. (2003). Informações contábeis por segmento de negócios. Revista de Contabilidade do Mestrado em Ciências Contábeis da UERJ. 8(2), 71-88.

Verrecchia, R. E. (2001). Essays on disclosure. Journal of Accounting and Economics. 32(1-3), 97-180. 